\title{
ACCENTUATED PERSONALITIES RELATED TO DAILY CIGARETTES SMOKING IN ROMANIAN COLLEGE STUDENTS - A CASE-CONTROL STUDY
}

\section{Cristina Petrescu ${ }^{1}$}

\begin{abstract}
:
Objective: In the study conducted accentuated personalities related to daily cigarette smoking in college students were investigated.

Material of study consisted in a case-sample of 349 daily smokers ( $49.3 \%$ females, $50.7 \%$ males) and a control-sample of 880 non-smokers (65.3\% women, $34.7 \%$ men) from an initial group of 1364 (aged 19-30 years) surveyed students.

The method was an observational case-control inquiry with two questionnaires applying: Health Questionnaire (60 items- 8 items for smoking) and Accentuated Personalities Questionnaire (88 items, alpha-Crohnbach index-0.823). Statistical analysis (chi square and gamma correlation) was performed by SPSS 20 Program.

Results: Three accentuated personalities were more prominent in daily smokers in comparison with nonsmokers and were related to daily-smoking with statistical significance: IV-unruly (answers to items: S30 $\chi^{2}=14.73, \gamma=0.23$; $S 42-\chi^{2}=30.25$, $\gamma=0.36$; and S52- $\chi^{2}=32.71, \gamma=0.35$; Sig.0.000), I-demonstrative $\left(S 7-\chi^{2}=18.89, \gamma=0.27\right.$; S44- $\chi^{2}=16.24, \gamma=0.27$; and S88$\chi^{2}=20.05, \gamma=0.27$; Sig.0.000) and VII-cyclothymic nature (S72- $\chi^{2}=32.24, \gamma=0.35$; Sig.0.000).
\end{abstract}

CONCLUSION: a relation between accentuated personalities and cigarette smoking is suggested.

UDC Classification: 614, 159.94; DOI: http://dx.doi.org/10.12955/cbup.v5.953

Keywords: cigarette smoking, accentuated personality, college students

\section{Introduction}

The traits of accentuated personalities exhibited at high-intensity levels affect human personality, and when they are emphasized even more, they can disrupt the structure of the personality. The direction of this disruption could be negative (psychiatric disease - personalities` disorders) (APA, 2013) or positive (accentuated personalities) (Leonhard, 1972). In this study, Leonhard analyzed both clinical cases and characters and typologies described by authors in fiction. Accentuated personalities questionnaire (Schmieschek, 1970; Nestor, 1975) explore the inner world of the person (feelings, intentions, attitudes, desires).

Personality structure through motivation (Bonilha et al., 2013), attitudes and self-efficacy (Mee, 2014; Ford et al., 2013) depression (Mee, 2014), and impulsivity (Balevich et al., 2013) was confirmed in recent research as being related to cigarette smoking.

Cigarette smoking inhibits the secretion of monoamine-oxidase (MAO), decreases hunger, anxiety, depression, and anger (Hughes, 2000), increases concentration capacity and stimulates Dopamine secretion (Robins \& Regier, 1991). In another study, the most robust indicator of vulnerability to high levels of self-reported smoking dependence was a general vulnerability to depression and negative emotions (Kahler et al., 2010). Cigarette smoking is a behavior that has become a growing problem among college students.

The aim of this study was to investigate the relation between accentuated personalities and daily cigarette smoking in college students.

\section{Material and method}

Participants

This study was performed on a sample comprised of 1364 college students $(60.7 \%$ females and $39.3 \%$ males, aged 19-30 years) chosen from 13 universities through stratified random sampling. From the initial group 2 samples were selected (cluster sampling): the case-sample (349 daily smoker students, 49.3\% females and 50.7\% males) and the control-sample (880 nonsmoker students, $65.3 \%$ females and $34.7 \%$ males). I did not consider occasional smokers (9.9\% students).

Material and procedure

\footnotetext{
1 “Victor Babes" University of Medicine and Pharmacy Timisoara/ Romania, cpetrescu64a@ yahoo.com
} 
The method was a case-control observational inquiry applying two questionnaires: Health Questionnaire (60 items from which 8 items for smoking were selected) and Accentuated Personalities Questionnaire (PA - 88 items).

The reliability of the Health Questionnaire (HQ) was good for couples of questions: q36, q37 - alphaCrohnbach index $=0.702$ and q41, q42 - alpha Cronbach's index $=0.844$. These items referred to: $\mathrm{q} 36$ "How often do you smoke at present, in a month?"; q37 "How often have you smoked in the past, in a month?"; q41 "How frequently do the family members smoke in a month?"; q42 "What is your motivation for smoking?".

The reliability of Accentuated Personalities Questionnaire (PA - "H. Schmieschek" Questionnaire) (Schmieschek, 1970; Nestor, 1975) was good - alpha-Crohnbach index $=0.823$. The items (marked with S) refer to symptoms of 10 accentuated personalities: I-demonstrative (12 items), II-hyperexact (12 items), III-hyperperseverant (12 items), IV-unruly (8 items), V-hyperthymic (8 items), VIdysthymic (8 items), VII-cyclothymic (8 items), VIII-exalted (4 items), IX-anxious (8 items), Xemotive ( 8 items). The application of both questionnaires was: individual, anonymous, 1 hour and a half long; with free consent and with an explanation of the aim of the study. Accentuated personalities profiles (Schmieschek, 1970; Nestor, 1975) of daily smoker and nonsmoker students were built and accentuated personalities between daily smokers and nonsmokers were compared. Roman numerals indicating each of accentuated personalities were kept in the same form in the profiles built. Statistical analysis (chi square, Fisher tests and gamma correlation) was performed by SPSS 20 Program.

\section{Results}

Smoking behavior among college students

Daily smoking behavior was present in the past (25.3\% students) and maintained in the present $(25.6 \%$ students). A gender difference of daily smokers in favor of males (33\% males and $20.8 \%$ females) was registered. A percentage of current nonsmokers (5.92\%) were in the past occasional smokers $(16.12 \%)$. The pattern of daily cigarette smoking was offered mainly by the father $(29.1 \%)$, the partner $(19.2 \%)$ and the mother $(17.9 \%)$ for the entire sample, and equally by the father $(40.1 \%)$ and the partner $(40.1 \%)$ and less frequently by the mother $(30.1 \%)$ for the daily smokers. Although the investigated students entirely agree that smoking is an unhealthy habit (48.5\% -entire sample, $59.3 \%$ daily smokers), they also totally agree that smoking calms them when they are nervous (15\% -entire sample, $41.8 \%$-daily smokers) and that it is a way to relax (14.9\% -entire sample, $45.6 \%$-daily smokers). The students' age when they began to smoke was 15 years (median=15, mean $=15.25$ with $\mathrm{SD}=3.35$ years). They used to smoke half a pack of cigarettes/day (mean=10 cigarettes). $47.44 \%$ of smokers tried to give up smoking and only $9.26 \%$ affirmed that they did manage to do so. A real difference of $5.9 \%$ between the present and the past non-smoker students was found.

Accentuated personalities of daily smoker and nonsmoker students

Most symptomatic (frequency of symptoms higher than 50\%) accentuated personalities (Vhyperthymic, III-hyperperseverant and X-emotive) were similar for the initial group and daily smoker students and different for the initial group and nonsmoker students (V, X and III) (figure 1).

Three accentuated personalities were more symptomatic in daily smoker group than they were in nonsmoker students: IV-unruly $(75 \% / 50 \%)$, I-demonstrative $(66.4 \% / 49.8 \%)$ and VII-cyclothymic nature $(62.5 \% / 50 \%)$. The IX-anxious $(37.5 \% / 12.5 \%)$ and VI-dysthymic $(25 \% / 12.5 \%)$ were not accentuated personalities (under 50\% of symptomatic answers) (figure 1).

Three other accentuated personalities were more symptomatic in nonsmoker than in daily smoker students: II-hyperexactly (58.1\%/49.8\%), VIII-exalted (75\%/50\%) and X-emotive (87.5\%/75\%). Still, daily smokers were symptomatic as emotive nature, too (figure 1).

Significant statistical differences were found between daily smoker and nonsmoker students for three accentuated personalities and one accentuated personality between nonsmoker and daily smoker students:

- IV-Unruly nature - There is a significant statistical difference (table 1) between the frequencies of positive answers of daily smokers and nonsmokers to the items: S30 - "Are you quickly angry?" (Yes - 56.44\% daily smokers and Yes - $44.32 \%$ non-smokers); S42 - "Did you ever run away from home, when you were a child?" (Yes - 34.39\% daily smokers and Yes 
- 19.57\% for nonsmokers); S52 - "When someone upset you a lot and intentionally, are you likely to lose control and start a fight?" (Yes - 61.03\% daily smokers and Yes - 31.60\% nonsmokers).

- I-Demonstrative nature - A significant statistical difference (table 1) was also found between the rate of positive answers of daily smokers and nonsmokers to the items: S7 - "Usually, in a friendly meeting, are you in the center of the others' attention?" (Yes - $60.11 \%$ daily smokers and Yes - 46.14\% non-smokers); S44 - "Has it ever happened to you that you became so troubled by conflicts or grievances that it became impossible for you to work?" (Yes - 33.91\% daily smokers and Yes $-22.73 \%$ non-smokers); S88 - "If you were involved in acting in a theatrical production would you become so involved in the role you were playing on a stage that you could completely forget you were actually someone else?" (Yes - 54.31\% daily smokers and Yes - 40.23\% of nonsmokers), and S51 - "Would you dislike to give a speech in public?" (No - 64.65\% daily smoker and No - $54.20 \%$ in nonsmoker students).

- VII-cyclothymic nature - A statistically significant difference (table 1) was noticed between the answers of daily smokers and nonsmokers to the item S72 - "Can you change your mood by alcohol consumption?" (Yes - 66.95\% in daily smokers and Yes $-48.51 \%$ in nonsmokers), too.

- X-emotive nature - A significant statistical difference (table 1) was found between the "Yes" answers of nonsmoker and daily smoker students to the items: S3 - "Do you burst into tears easily?" (78.69\% - nonsmokers and 21.03\% - daily smokers), S13 - "Are you very merciful?" ( $75.57 \%$ - nonsmokers and $24.42 \%$ - daily smokers), S57 - "Can a tragic movie affect you so much that you burst into tears?" (76\% - nonsmokers and 24\% - daily smokers), S79 - "Are you very affected by the suffering of other people?" (63.31\% - nonsmokers and $36.87 \%$ - daily smokers), and between the "No" answer to the item S25 - "Are you able to sacrifice an animal?" (66.66\% - nonsmokers and 33.33\% - daily smokers).

A positive gamma correlation between the answers to specific items of IV-unruly nature, Idemonstrative nature (except item S51 where the "No" answer is rated as positive), VII-cyclothymic nature and daily cigarette smoking sustains these results (table 2). A negative gamma correlation was found between the "Yes" answers to the questions of X-emotive nature and cigarette smoking (table 2).

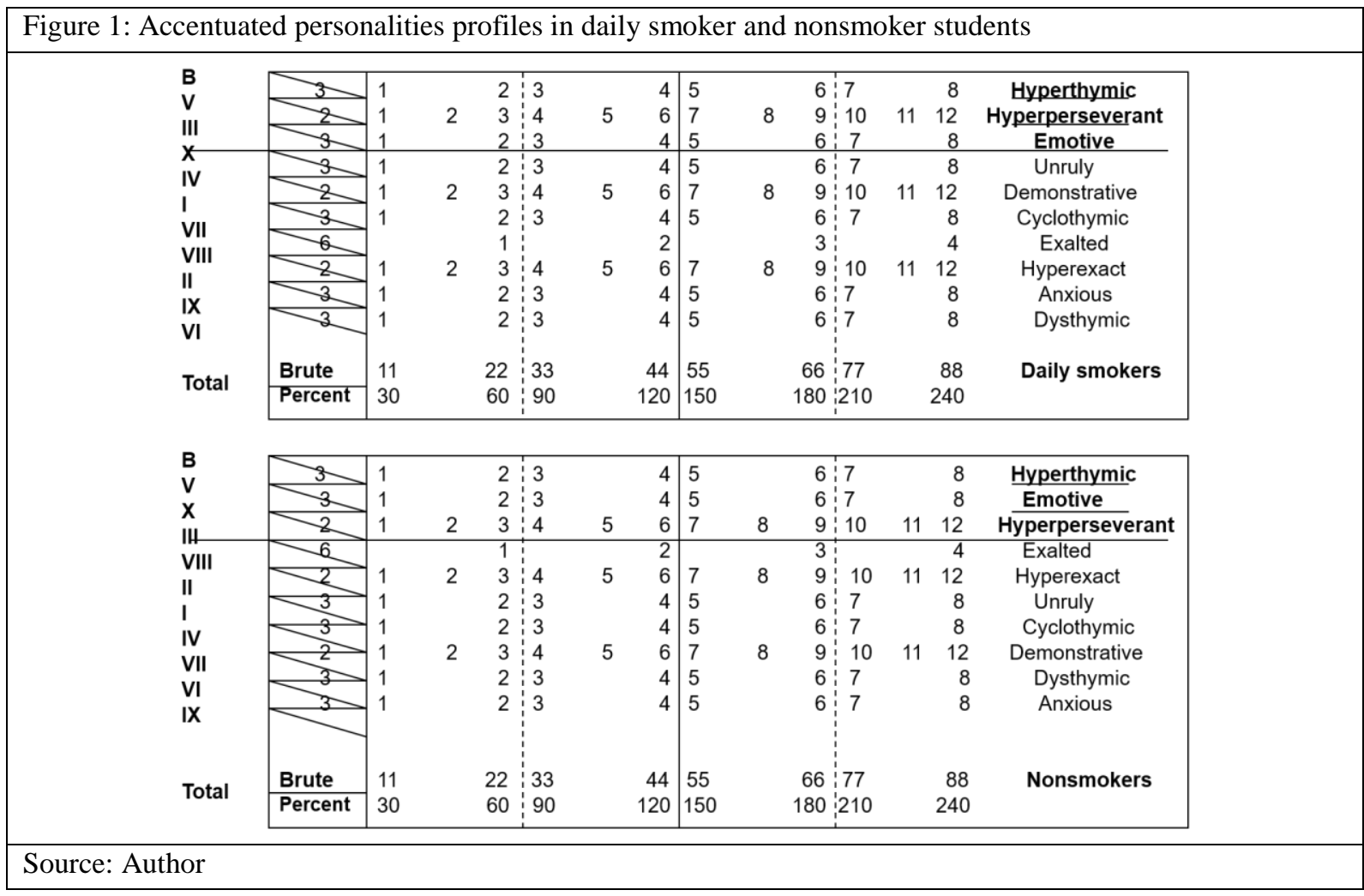




\begin{tabular}{|c|c|c|c|c|c|}
\hline \multirow{2}{*}{$\begin{array}{l}\text { Accentuated personalities } \\
\text { (PA) } \\
\text { Statistics by PA items }\end{array}$} & \multicolumn{3}{|c|}{ Pearson Chi-square } & \multicolumn{2}{|c|}{ Fisher's Exact Test(a) } \\
\hline & Value & df & $\begin{array}{c}\text { Asymp. Sig. } \\
\text { (2-sided) }\end{array}$ & $\begin{array}{l}\text { Exact Sig. } \\
\text { (2-sided) }\end{array}$ & $\begin{array}{l}\text { Exact Sig. } \\
\text { (1-sided) }\end{array}$ \\
\hline IV-Unruly S30 & 14.734(b) & 1 & 0.000 & 0.000 & 0.000 \\
\hline S42 & $30.257(b)$ & 1 & 0.000 & 0.000 & 0.000 \\
\hline S52 & $32.712(b)$ & 1 & 0.000 & 0.000 & 0.000 \\
\hline I-Demonstrative S7 & $18.896(b)$ & 1 & 0.000 & 0.000 & 0.000 \\
\hline S44 & $16.246(b)$ & 1 & 0.000 & 0.000 & 0.000 \\
\hline S88 & $20.052(b)$ & 1 & 0.000 & 0.000 & 0.000 \\
\hline S51 & $10.751(b)$ & 1 & 0.001 & 0.001 & 0.001 \\
\hline VII-Cyclothymic S72 & $32.245(b)$ & 1 & 0.000 & 0.000 & 0.000 \\
\hline X-Emotive S3 & 39.893(b) & 1 & 0.000 & 0.000 & 0.000 \\
\hline S13 & 27.553(b) & 1 & 0.000 & 0.000 & 0.000 \\
\hline S57 & $25.869(b)$ & 1 & 0.000 & 0.000 & 0.000 \\
\hline $\mathbf{S} 25$ & $13.025(b)$ & 1 & 0.000 & 0.000 & 0.000 \\
\hline S79 & $16.795(b)$ & 1 & 0.000 & 0.000 & 0.000 \\
\hline
\end{tabular}

\begin{tabular}{|c|c|c|c|c|c|c|}
\hline \multirow{2}{*}{$\begin{array}{c}\begin{array}{c}\text { Accentuated } \\
\text { personalities (PA) }\end{array} \\
\text { IV-Unruly S30 }\end{array}$} & \multicolumn{2}{|c|}{ Statistics by PA items } & \multirow{2}{*}{\begin{tabular}{|l} 
Value \\
0.366
\end{tabular}} & \multirow{2}{*}{$\begin{array}{c}\begin{array}{c}\text { Asymp. } \\
\text { Std. } \\
\text { Error(a) }\end{array} \\
0.061\end{array}$} & \multirow{2}{*}{$\begin{array}{c}\text { Approx. } \\
\text { T(b) } \\
5.106\end{array}$} & \multirow{2}{*}{$\begin{array}{c}\begin{array}{c}\text { Approx. } \\
\text { Sig. }\end{array} \\
0.000\end{array}$} \\
\hline & Ordinal by Ordinal & Gamma & & & & \\
\hline S42 & Ordinal by Ordinal & Gamma & 0.366 & 0.061 & 5.106 & 0.000 \\
\hline S52 & Ordinal by Ordinal & Gamma & 0.351 & 0.057 & 5.762 & 0.000 \\
\hline I-Demonstrative S7 & Ordinal by Ordinal & Gamma & 0.271 & 0.060 & 4.381 & 0.000 \\
\hline S44 & Ordinal by Ordinal & Gamma & 0.271 & 0.064 & 3.828 & 0.000 \\
\hline S88 & Ordinal by Ordinal & Gamma & 0.277 & 0.059 & 4.451 & 0.000 \\
\hline S51 & Ordinal by Ordinal & Gamma & -0.210 & 0.062 & -3.337 & 0.001 \\
\hline VII-Cyclothymic S72 & Ordinal by Ordinal & Gamma & 0.356 & 0.058 & 5.832 & 0.000 \\
\hline X-Emotive S3 & Ordinal by Ordinal & Gamma & -0.383 & 0.055 & -6.311 & 0.000 \\
\hline S13 & Ordinal by Ordinal & Gamma & -0.345 & 0.061 & -4.923 & 0.000 \\
\hline S57 & Ordinal by Ordinal & Gamma & -0.322 & 0.059 & -4.867 & 0.000 \\
\hline S25 & Ordinal by Ordinal & Gamma & -0.271 & 0.063 & -3.909 & 0.000 \\
\hline S79 & Ordinal by Ordinal & Gamma & 0.234 & 0.063 & 3.493 & 0.000 \\
\hline
\end{tabular}

a Not assuming the null hypothesis; b Using the asymptotic standard error assuming the null hypothesis.

Source: Author

\section{Discussion}

College students aged between 19-30 years (young adult - intimacy/isolation stage of human psychosocial development (Erikson, 1968) were approached in this study. Cigarette smoking is a risk behavior that starts and becomes an addiction at this age group. The smoking habit appears and continues due to behavioral problems manifested in early adolescence (Brook et al., 2008). A real danger of cigarette smoking in young adults is that they become perpetual smokers (McLure et al., 
2013). In this study daily smokers in the past are daily smokers at present. Daily smokers proved to have frequent positive responses to active smoking-related cues which may play an important role in maintaining smoking behavior (Haight et al., 2012). Family pattern (the father daily smoker and the partner daily smoker) was significant in this study. The smoking patterns could be associated with parenting styles (Bottorff, 2010) and with the perceived family life (Foxcroft \& Lowe, 1995). In the conducted study the students chose relaxation and calming when they are nervous as the main motivations for cigarette smoking. The nicotine interacts with all levels of motivation (West, 2009), therefore dealing with stressful situations (Fields et al., 2009) can influence decisions to smoke. Other studies found that young people with low confidence in their ability to avoid smoking would have higher levels of smoking intention and smoking behavior (Hassandra et al., 2011). Combating cigarette addiction requires attention to the predictors of cigarette smoking (Burris et al., 2013) and to the role of gender in preventive actions against smoking (Lotrean \& De Vries, 2012).

I found differences in cigarette smoking between male daily smokers and female daily smokers. In research literature smoking continues to be more frequently found in more masculine populations (Mahfouz et al., 2014) possibly due to a relation between smoking and masculinity (White et al., 2012) than in more feminine populations, where female subjects reported concerns about their weight (Morgenstern et al., 2010).

In research literature, cigarette smoking was approached in relation to personality traits (Patton et al., 1997). In this study, the profiles of the accentuated personalities in daily smokers and nonsmokers were different. The statistical results of this study reveal that certain accentuated personalities (IVunruly, I-demonstrative, VII-cyclothymic) are more frequent and more symptomatic in daily cigarette smokers than in nonsmokers, in a population of healthy young adults. Therefore, IV-unruly nature presented significant statistical differences between daily cigarette smokers and nonsmokers. The increased anger (S30), the tendency to run away from home in childhood and breaking the rules (S42) and the lack of control of aggressive behavior and fighting (S52) found in the daily smokers in this study argue for the role of smoking in decreasing anger, impulsivity, hostility and the presence of sociopath behavior that is mentioned in literature (Hughes, 2000; Patton et al., 1997). Another study (Littlefield \& Sher, 2012) demonstrated that from ages 18 to 35, changes in smoking involvement are significantly associated with changes in impulsivity. Other studies reveal more frequent engagement of smokers in antisocial behaviors (Alloy et al., 2009) and a strong association between antisocial personality disorder and smoking (Zvolensky et al., 2011).

This study found that I-demonstrative nature was more symptomatic in daily cigarette smokers than in nonsmokers. The tendency of daily cigarette smokers to be in the center of attention (S7), to display emotion openly (S88) and to like being on a stage (S51 - negative answer was considered symptomatic) is sustained by literature through extraversion personality characteristic in cigarette smokers (Ferguson, 2013). Yet, demonstrative nature, as Karls Leonhard affirms, is difficult to compare with present-day literature research, which refers especially to extraversion personality characteristic. However, extraversion in combination with neuroticism increases the risk of cigarette smoking dependency (Kleinjan et al., 2012).

Frequent changes of mood (VII-cyclothymic accentuated personality) were more frequently found in daily cigarette smokers than in nonsmokers in this study. Cyclothymia means stable feeling at a baseline level with the shift to an emotional high (symptoms similar to mania but less severe) or an emotional low (symptoms similar to depression but less severe). The greater tendency in daily smokers to change their mood by alcohol consumption (S72) - emotional high - was found in this study and it is supported by the way mania is approached in research literature. Research literature indicates impulsiveness as shared personality vulnerability for bipolar spectrum status in adult individuals (Alloy et al., 2009). Regular smoking also correlated with borderline personality disorder, that correlation being explained by common genetic factors (Distel et al., 2012).

This study showed that nonsmokers were much stronger in $\mathbf{X}$-emotive responses than daily smokers and a statistically significant difference was found in favor of nonsmoker students. Therefore, easily touching and expressing of his/her emotions (S79, S3), compassion (S13), easy changing of his/her disposition depending on external events (S57, S25) are more prominent in non-smokers over smokers. 
Two accentuated personalities remained constant in this study as being powerfully symptomatic and without significant statistical differences between smoker and nonsmoker students: V-hyperthymic and III-hyperperseverant. They are specific for the investigated stage of development intimacyisolation (young adults aged 19-30 years) (Erikson, 1968) and for the professional forming and performing.

A limitation of this research is that it is a qualitative one and the relation between daily cigarette smoking - and certain accentuated personalities is therefore only suggested.

\section{Conclusions}

This study offers a new perspective through which to look at daily cigarette smoking in young people - in relation to accentuated personalities. The main outcomes of this study showed profiles of different personalities in daily smokers and nonsmokers, an association of daily cigarette smoking with the traits of accentuated personalities (IV-unruly nature, I-demonstrative and VII-cyclothymic nature) and several aspects of smoking phenomena met in investigated populations. Therefore, the tendency of cigarette smoking to become an addiction, the role of the family pattern, gender differences, and relaxation and tranquilization as primary or important motivations for cigarette smoking were found.

Two accentuated personalities (V-hyperthymic and III-hyperperseverant) were similarly high symptomatic in the initial study group, case-sample and control-sample. X-emotive nature was more symptomatic in nonsmoker than in smoker students.

Knowing the accentuated personalities of young adults, practitioners can help them to avoid starting to smoke or can help daily smokers stop their smoking habit. This study suggests the existence of a relation between the traits of accentuated personalities in young adult daily smokers - and cigarette smoking.

\section{Acknowledgements}

The source of the data used in this article is the Project No. 402/7.11.2012, Health risk behavior in conjunction with psychological and personality traits in young people, founded by the Institute of Anthropology "Francisc I. Rainer", Romanian Academy. Project Coordinator Rada C.

\section{Conflict of interest}

Author declares she has no conflict of interest.

\section{Informed consent}

According to opinion no. 285/05.08.2013 issued by the Ethics Committee of the Institute of Anthropology „Francisc I. Rainer" research meets ethical standards stipulated by Act No. 206/2004, as amended by Ordinance 28/2011 on good practice in scientific research and technological development and innovation. All procedures followed were in accordance with the ethical standards of the responsible committee on human experimentation (institutional and national) and with the Helsinki Declaration of 1975, as revised in 2000 (5). Informed consent was obtained from all students for being included in the study.

\section{References}

Alloy, L., Bender, R., Wagner, C., Whitehouse, W., Abramson, L., Hogan, M., \& Harmon-Jones, E. (2009). Bipolar spectrum - substance use co-occurrence: Behavioral Approach System (BAS) sensitivity and impulsiveness as shared personality vulnerabilities. Journal of Personality and Social Psychology, 97(3):549-565.

American Psychiatric Associations. (2013). Diagnostic and Statistical Manual of Mental Disorders (Fifth ed.). Arlingon, VA: American Psychiatric Publishing.

Balevich, E. C., Wein, N. D., \& Flory, J. D. (2013). Cigarette smoking and measures of impulsivity in a college sample. Substance Abuse, 34(3):256-262.

Bonilha, A. G., de Souza, E. S., Sicchieri, M. P., Achcar, J. A., Crippa, J. A., \& Baddini-Martinez, J. (2013). A motivational profile for smoking adolescents. Journal of Addiction Medicine, 7(6):439-446.

Bottorff, J. L., Kelly, M. T., Oliffe, J. L., Johnson, J. L., Greaves, L., \& Chan, A. (2010). Tobacco use pattern in traditional and shared parenting families: a gender perspective Public Health, 10:239.

Brook, D., Brook, J., Zhang, C., Whiteman, M., Cohen, P., \& Finch, S. (2008). Developmental trajectories of cigarette smoking from adolescence to the early thirties: personality and behavioral risk factors. Nicotine and Tobaco Research, 10(8):1283-1291.

Burris, J. L., Wahlquist, A. E., \& Carpenter, M. J. (2013). Characteristics of cigarette smokers who wants to quit now versus quit later. Addictive Behaviors, 38(6):2257-2260. 
Distel, M., Trull, T., de Moor, M., Vink, J., Geels, L., van Beek, J., \& Boomsma, D. (2012). Borderline personality traits and substance use: genetic factors underlie the association with smoking and ever use of cannabis, but not high alcohol consumption. Journal of Personality Disorders, 26(6):867-879.

Erikson, E. H. (1968). Identity, youth and crisis. New York: Norton.

Ferguson, E. (2013) Personality is of central concern to understand health: towards a theoretical model for health psychology. Health Psychology Review, 7 (Suppl 1):S32-S70.

Fields, S., Leraas, K., Collins, C., \& Reynolds, B. (2009). Delay discounting as a mediator of the relationship between perceived stress and cigarette smoking status in adolescents. Behavioural Pharmacology, 20(5-6):455-460.

Ford, K. H., Oladapo, A. O., Sterling, L K., Diamond, P. M., Kelder, S. H., \& McAlister, A. (2013). Assessing the psychometric properties of smoking-related attitudes, self-efficacy, and intention among a diverse population of middle school students. Addictive Behaviors, 38(8):2378-2383.

Foxcroft, D. R., \& Lowe, G. (1995). Adolescent drinking, smoking and other substance use involvement: links with perceived family life. Journal of Adolescence, 18(2):159-177.

Haight, J., Dickter, C. L., \& Forestell, C. A. (2012). A comparison of daily and occasional smokers`implicit affective responses to smoking cues. Addicive Behaviors, 37(3):234-239.

Hassandra, M., Vlachopoulos, S. P., Kosmidou, E., Hatzigeorgiadis, A., Goudas, M., \& Theodorakis, Y. (2011). Predicting students` intention to smoke by theory of planned behaviour variables and parental influences across school grade levels. Psychology and Health, 26(9):1241-1258.

Hughes, J. R. (2000). Evidence for and against the self-medication hypothesis for smoking. International Journal of Neuropsychopharmacology, 3 (Suppl 1):S58.

Kahler, C., Leventhal, A., Daughters, S., Clark, M., Colby, S., Ramsey, S., \& Buka, S. (2010). Relationship of personality and psychiatric disorders to multiple domains of smoking motives and dependence in middle aged adults. Nicotine Tobacco Research, 12(4):381-389.

Kleinjan, M., Vitaro, F., Wanner, B., Brug, J., van den Eijnden, R., \& Engels, R. (2012). Predicting nicotine dependence profiles among adolescent smokers: the roles of personal and social-environmental factors in a longitudinal framework. $B M C$ Public Health, 12:196.

Leonhard, K. (1972). Personalitati accentuate in viata si literatura [Accentuated Personalities in life and literature]. Bucharest: Romanian Encyclopedic Publishing House.

Littlefield, A., \& Sher, K. (2012). Smoking desistance and personality change in emerging and young adulthood. Nicotine Tobacco Research, 14(3):338-342.

Lotrean, L. M., \& D Vries, H. (2012). Identifying gender differences among Romanian non-smoking junior high school students. Central European Journal of Public Health, 20(1):33-37.

Mahfouz, M. S., Alsanosy, R. M., Gaffar, A. M., \& Makeen, A. (2014). Tobacco use among university students of Jazan region: gender differences and associated factors. BioMed Research International, doi: 10:1155/2014/279231.

McLure, L. A., Arheart, K. L., Lee, D. J., Sly, D. F., \& Dietz, N. A. (2013). Young adult former ever smokers: the role of type of smoker, quit attempts, quit aids, attitudes/beliefs, and demographics. Preventive Medicine, 57(5):690-695.

Mee, S. (2014). Self-efficacy: a mediator of smoking behavior and depression among college students. Pediatric Nursing, 40(1):9-15

Morgenstern, M., Isensee, B., \& Hanewinkel, R. (2010). Gender, smoking and weight concerns: relationship to elf-reported body mass index (BMI). Przeglad Lekarsky, 67(10):826-829.

Patton, D., Barnes, G. E., \& Murray, R. P. (1997). A personality typology of smokers. Addictive Behaviors 22(2):269-273.

Robins, L. N., \& Regier, D. A. (1991). Psychiatric disorders in America: the epidemiologic catchment's area study. New York: Free Press; 116-154.

Schmieschek, H. (1970). Questionnaire for the determination of accentuated personalities. Psychiatrie, Neurologie und Medizinische Psychologie, 22(10):378-381.

Nestor, I. M. (1975). Explorarea Personalității Accentuate - Chestionarul H. Schmieschek [Exploring of the Accentuated Personality - H. Schmieschek Questionnaire]. Retrieved June 15, 2014, from xa.yimg.com/kq/.../P\%5B1\%5D.A.personalitati+accentuate.doc.

West, R. (2009). The multiple facets of cigarette addiction and what they mean for encouraging and helping smokers to stop. COPD, 6(4):277-283.

White, C., Oliffe, J. L., \& Bottorff, J. L. (2012). Fatherhood, smoking, and secondhand smoke in North America: an historical analysis with a view to contemporary practice. American Journal of Men`s Health, 6(2):146-155.

Zvolensky, M., Jenkins, E., Johnson, K., \& Goodwin, R. (2011). Personality disorders and cigarette smoking among adults in the United States. Journal of Psychiatric Research, 45(6):835-841. 